\title{
Persepsi Masyarakat Terhadap Kebutuhan Pelayanan Rumah Sakit Syariah di Kota Yogyakarta
}

\author{
Community Perception Of The Need For Sharia Hospital Services In \\ Yogyakarta City
}

\begin{abstract}
Rochana Rulyandari*, Sitti Nur Djannah, Intan Wahyuni Tukiyo
Fakultas Kesehatan Masyarakat, Universitas Ahmad Dahlan

Emial: Ruliyandari.fkmuad@gmail.com*, Sitti.nurdjannah@ikm.uad.ac.id, Intanwahyunitukiyo@gmail.com

Abstrak:

Rumah sakit syariah merupakan rumah sakit yang dalam aktifitasnya atau pengoperasionalannya berdasarkan pada maqashid syariah. Rumah sakit syariah dibuat denlgan standart, sistem dan mutu yang sesuai dengan syariat islam. Penelitian ini dilakukan pada masyarakat kota Yogyakarta. Dengan tujuan untuk melihat kebutuhan masyarakat terhadap rumah sakit syariah. Penelitian ini menggunakan metode deskriptif analitik, dengan teknik pengambilan sampel menggunakan random sampling dengan jumlah sampel sebanyak 43 orang. Data penelitian ini diambil menggunakan kuesioner elektronik. Analisis data dilakukan menggunakan analisis deskriptif. masyarakat sebagian besar setuju bahwa rumah sakit telah melaksanakan prinsip-prinsip syariat islam dalam melakukan pelayanan kesehatan pada pasien. Melakukan pelayanan sesuai gender pasien, berinteraksi dan memiliki prinsip sosial, memiliki lingkungan yang nyaman sesuai syariat islam. Sebagian besar perlu terus menyesuaikan update pelayanan kesehatan yang berbasis syariah, sehingga meningkatkan kepuasan pasien.
\end{abstract}

Kata Kunci: Pelayanan Kesehatan, Rumah Sakit Syariah, Standar Rumah Sakit Syariah.

\begin{abstract}
Sharia hospital is a hospital whose activities or operations are based on maqashid sharia. Sharia hospitals are made with standards, systems and quality in accordance with Islamic law. This research was conducted on the people of the city of Yogyakarta. With the aim of seeing the community's need for sharia hospitals. This study used a descriptive analytic method, with the sampling technique using random sampling with a sample size of 43 people. The research data were taken using an electronic questionnaire. Data analysis was performed using descriptive analysis. Most people agree that the hospital has implemented the principles of Islamic law in providing health services to patients. Providing services according to the patient's gender, interacting and having social principles, having a comfortable environment according to Islamic law. Most of them need to continue to adjust sharia-based health service updates, thereby increasing patient satisfaction.
\end{abstract}

Keywords: Health Services, Sharia Hospitals, Sharia Hospital Standards. 


\section{Pendahuluan}

Rumah sakit syariah merupakan rumah sakit yang dalam aktifitasnya atau pengoperasionalannya berdasarkan pada maqashid syariah (tujuan diadakannya syariah). Majelis Upaya Kesehatan Islam Seluruh Indonesia (MUKISI) dan Dewan Syariah Nasional (DSN) bekerja sama untuk membuat standar dan sertifikasi untuk sistem rumah sakit berbasis syariah. yaitu seperti penjagaan agama, jiwa, keturunan, akal dan penjagaan harta. Rumah sakit syariah dilaksanakan berpedoman pada fatwa dewan syariah nasional majelis ulama Indonesia No. 107/DSN-MUI/X/2016 menjelaskan tentang pedoman penyelenggaraan Rumah Sakit berdasarkan prinsip syariah. Rumah sakit Islam memberikan jaminan akan adanya pelayanan sesuai syariah, penyelamatan akidah Islam dan penerapan manajemen berbasis syariah ${ }^{1,2}$

Menurut Kotler dalam Hafid pelayanan adalah setiap tidakan maupun kegiatan yang ditawarkan oleh satu pihak ke pihak yang lainnya yang dasarnya tidak berwujud dan tanpa memberikan efek kepemilikan apapun. Penelitian yang dilakukan Sari,dkk menunjukkan ada hubungan antara pelayanan keperawatan berbasis syariah dengan loyalitas pasien di RSISA Semarang, hal ini dapat dikatakan bahwa pasien pelayanan kesehatan yang diterapkan oleh Rumah Sakit Islam Sultan Agung Semarang menerapkan konsep islami yang membuat pasien menjadi nyaman dan tenang karena mendapat perawatan secara jasmani dan rohani $^{3,4}$.

Selain pelayanan kesehatan rumah sakit syariah di Semarang, pelayanan kesehatan rumah sakit berbasis syariah di kota Yogyakarta juga perlu dilihat dengan banyaknya jumlah rumah sakit yang sudah merapkan ajaran islam. Sehingga, dengan adanya rumah sakit syariah di Yogyakarta pelayanan kesehatan yang dilakukan menjadi lebih baik dan memberikan rasa nyaman terhadap pasien maupun keluarga pasien.

Sunawi mengatakan bahwa pembeda antara rumah sakit islam dengan rumah sakit non-islam terdapat pada karakter keyakinan dan penyerahan segala sesuatu pada Allah SWT (rabbaniyah). Sedangkan pada karakter yang lain yaitu akhlaqiyah, waqi'yah, dan insaniyah, merupakan unsur-unsur pada jasa rumah sakit non-islam sebagai orientasi pelayanan namun berbeda dalam penerapan dan pengembangan pelayanan terhadap pasien ${ }^{5}$. Penelitian ini dilakukan pada masyarakat Kota Yogyakarta. Dengan tujuan untuk mengetahui presepsi masyarakat terhadap kebutuhan pelayanan kesehatan melalui rumah sakit syariah.

\section{Metode}

Penelitian ini menggunakan metode deskriptif analitik, dengan teknik pengambilan sampel menggunakan total sampling. Penelitian ini menggunakan responden yang berjumlah 43 orang yang merupakan pengguna sarana rumah sakit baik rumah sakit syariah maupun rumah sakit biasa.Pengumpulan data diambil menggunakan kuesioner elektronik menggunakan google form. Kemudian, analisis data dilakukan menggunakan analisis deskriptif dan disajikan dalam bentuk tabulasi dan grafik. 


\section{Hasil dan Pembahasan}

\section{Hasil Penelitian}

Berdasarkan hasil penelitian yang telah dilakukan pada masyarakat, didapatkan hasil dan diuraikan dalam bentuk distribusi frekuensi karakteristik responden sebagai berikut :

Tabel 1. Distribusi frekuensi karakteristik Responden

\begin{tabular}{lrr}
\hline Variabel & F & \multicolumn{2}{c}{$\%$} \\
\hline Jenis Kelamin & 18 & 42 \\
\hline Laki-laki & 25 & 58 \\
Perempuan & & \\
\hline Usia & 7 & 16 \\
19 - 25 tahun & 17 & 40 \\
26 - 35 tahun & 14 & 33 \\
56 - 50 tahun & 4 & 9 \\
51 - 60 tahun & 1 & 2 \\
\hline Pendidikan & & \\
\hline D3 & 2 & 5 \\
D4 & 1 & 2 \\
S1 & 29 & 67 \\
S2 & 6 & 14 \\
SMA & 1 & 2 \\
Profesi (apt\&ners) & 4 & 9 \\
\hline Pekerjaan & & \\
\hline ASN non PNS & 1 & 2 \\
Apoteker dan Guru & 2 & 5 \\
Bidan & 1 & 2 \\
Fisikawan Medik & 1 & 2 \\
Guru & 21 & 49 \\
Karyawan & 1 & 2 \\
Karyawan Swasta & 3 & 7 \\
Mahasiswa & 2 & 5 \\
PNS & 3 & 7 \\
Pensiunan & 1 & 2 \\
Solri & 1 & 2 \\
TTK & 3 & 7 \\
Wiraswasta & 1 & 2 \\
Total & 2 & 5 \\
\hline & 43 & 100 \\
\hline
\end{tabular}

Berdasarkan Tabel 1 menunjukkan bahwa sebagian besar responden berjenis kelamin perempuan $(58 \%)$, memiliki pendidikan terakhir sarjana $(67 \%)$ dan bekerja sebagai guru (49\%). 


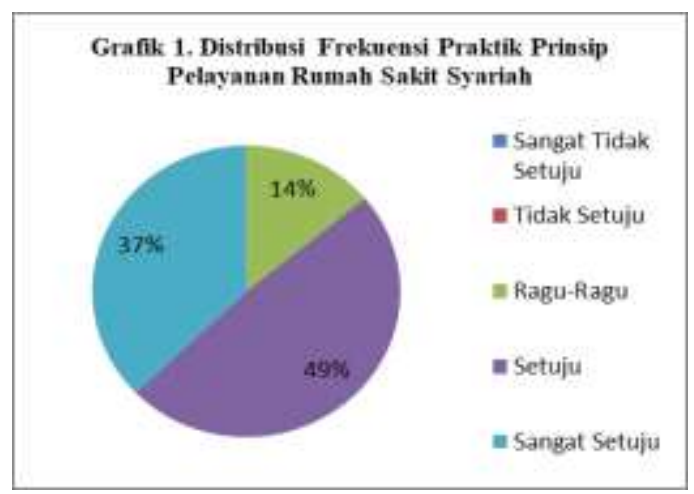

Grafik 1. Distribusi Frekuensi Praktik Prinsip Pelayanan Rumah Sakit Syariah

Berdasarkan grafik 1 dapat diketahui sebanyak $49 \%$ responden setuju bahwa rumah sakit telah melaksanakan prinsip-prinsip syariat islam dalam melakukan pelayanan kesehatan pada pasien. Namun, 14\% responden menunjukkan hasil yang ragu-ragu terhadap prinsip pelayanan di rumah sakit syariah. Kemudian, sebanyak $37 \%$ responden sangat setuju terhadap prinsip pelayanan di rumah sakit syariah.

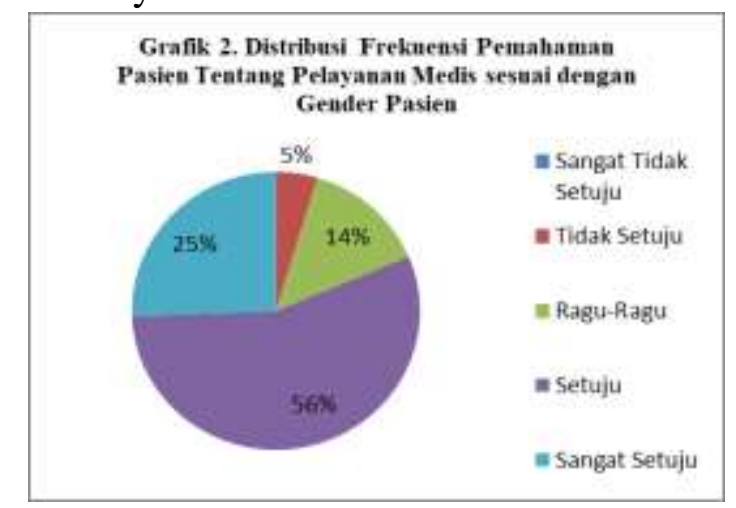

Grafik 2. Distribusi Frekuensi Pemahaman Pasien Tentang Pelayanan Medis sesuai dengan Gender Pasien

Berdasarkan grafik 2 dapat diketahui masyarakat sebagai pasien sebagian besar setuju sebanyak $56 \%$ bahwa pelayanan medis di rumah sakit syariah sudah menerapkan pelayanan sesuai gender. Namun, terdapat 5\% masyarakat yangtidak setuju bahwa rumah sakit syariah menjalankan pelayanan medis sesuai dengan gender pasien. 


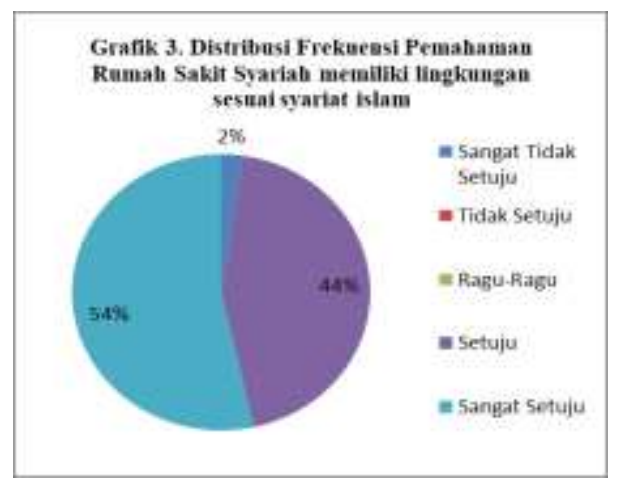

Grafik 3. Distribusi Frekuensi Pemahaman Rumah Sakit Syariah memiliki lingkungan sesuai syariat islam

Berdasarkan grafik 3 diketahui sebagian besar masyarakat setuju (54\%) bahwa rumah sakit syariah harus memiliki lingkungan yang nyaman teduh dan bersih sesuai dengan syariat islam, sehingga pasien merasa senang menjalani perawatan selama di rumah sakit.namun, hanya sebesar $2 \%$ dari masyarakat yang sangat tidak setuju bahwa rumah sakit syariah memiliki lingkungan dan suasana yang sesuai dengan syariah islam.

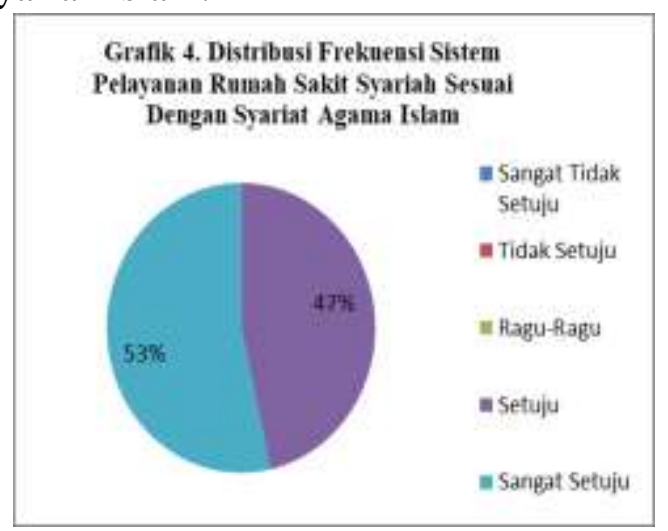

Grafik 4. Distribusi Frekuensi Sistem Pelayanan Rumah Sakit Syariah Sesuai Dengan Syariat Agama Islam

Berdasarkan grafik 4 menunjukkan bahwa sebanyak 53\% masyarakat memilih sangat setuju bahwa rumah sakit syariah sudah menerapkan system pelayanan kesehatan sesuai dengan syariat islam. Dan, sebanyak $47 \%$ masyarakat setuju bahwa system pelayanan rumah sakit syariah sudah menerapkan syariat islam. 


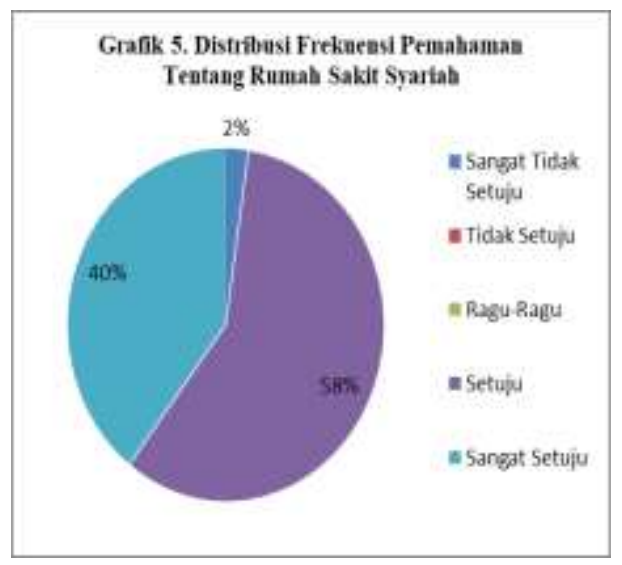

Grafik 5. Distribusi Frekuensi Pemahaman Tentang Rumah Sakit Syariah

Berdasarkan grafik 5 menunjukkan hasil bahwa sebanyak 58\% masyarakat setuju bahwa rumah sakit syariah sudah memahami konsep rumah sakit syariah yang ada di sekitar tempat tinggal mereka. Namun, hanya sebesar $2 \%$ masyarakat yang sangat tidak setuju tentang konsep pemahaman rumah sakit syariah.

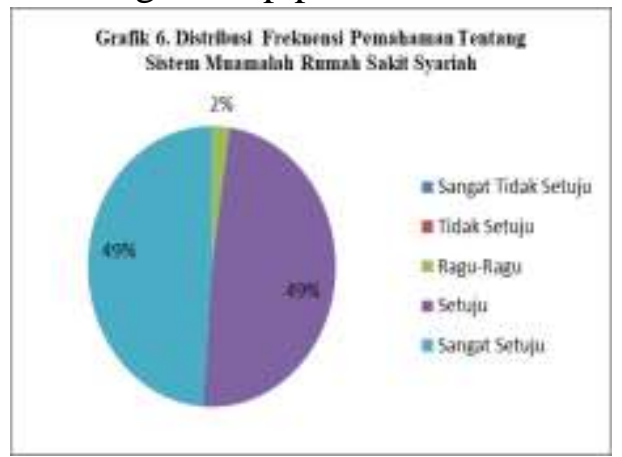

Grafik 6. Distribusi Frekuensi Pemahaman Tentang Sistem Muamalah Rumah Sakit Syariah

Berdasarkan grafik 6 menunjukkan bahwa sebanyak 49\% masyarakat sangat setuju dengan konsep rumah sakit syariah yang sesuai dengan sistem bermuamalah atau berinteraksi sesuai dengan ajaran islam._Sebaliknya hanya sebesar 2\% masyarakat yang mengatakan ragu-ragu bahwa interaksi yang terjadi di rumah sakit syariah sudah sesuai dengan sistem mualamah ajaran islam.

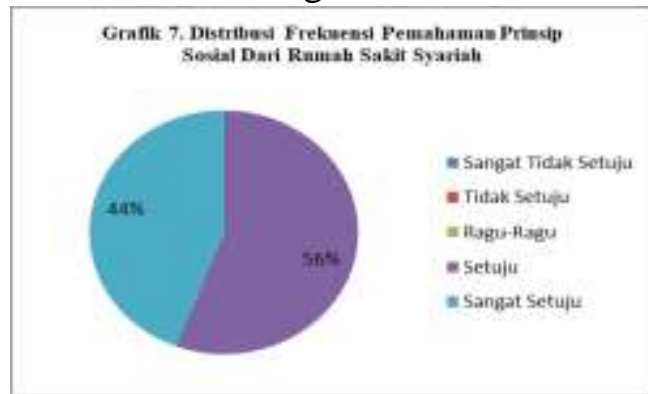

Grafik 7. Distribusi Frekuensi Pemahaman Prinsip Sosial Dari Rumah Sakit Syariah 
Berdasarkan grafik 7 menunjukkan hasil bahwa sebanyak 56\% masyarakat setuju bahwa rumah sakit syariah tidak hanya menerapkan prinsip ajaran islam namun juga menerapkan prinsip social dalam melakukan pelayanan kesehatan terhadap pasien. Kemudian, sebanyak $44 \%$ masyarakat setuju dengan prinsip social yang juga dilakukan oleh rumah sakit syariah

\section{Pembahasan}

Rumah sakit dengan pelayanan yang berbasis syariah memiliki tanggung jawab baik secara pelayanan kesehatan dan memberikan pelayanan kesehatan yang diberikan kepada pasien harus berdasarkan dengan menjaga akidah, ibadah dan muamalah yang sesuai dengan prinsip-prinsip islam ${ }^{6}$. Penelitian yang dilakukan oleh Hafid,dkk mendapatkan hasil bahwa pelayanan kesehatan yang dibarengi dengan prinsip-prinsip syariah dapat meningkatkan kepuasan pasien baik secara parsial, stimulan dan perawatan ${ }^{4,7}$.

Sebanyak 56\% Masyarakat setuju bahwa pelayanan pasien sesuai gender sangat diperlukan, terutama mengenai pelayanan yang bersifat pribadi. Sesuai dengan penelitian yang dilakukan oleh Yusuf bahwa pelayanan pasien pada RS Islam Banjarmasin dibuat agar meminimalisir dari perbuatan maksiat dan aktifitas lain, dimana terdapat pembatasan jam kunjung dan pelayanan yang sensitif seperti ppemasangan kateter oleh perawat sesuai dengan gender pasien ${ }^{8}$.

Hasil penelitian ini menunjukkan sebanyak 54\% masyarakat menilai Rumah sakit syariah yang ada di Yogyakarta memiliki lingkungan yang nyaman teduh dan bersih sesuai syariat islam. Hasil penelitian Yusuf juga menunjukkan hasil yang sama, RS Islam Banjarmasin memiliki petugas pelayanan kebersihan yang melakukan dan menjaga kebersihan rumah sakit secara terus menerus lingkungan rumah sakit, serta kamar pasien jika diminta tanpa biaya tambahan. Dalam islam, sebuah hadist mengatakan bahwa "Kebersihan adalah sebagian daripada Iman", sehingga dapat dikatakan bahwa jika lingkungan rumah sakit terjaga kebersihan dan kenyamanannya maka masyarakat terutama pasien yang membutuhkan pelayanan kesehatan di Rumah Sakit Syariah akan senang dan nyaman berada dilingkungan rumah sakit tersebut. Serta, memiliki dampak yang positif bagi pasien dalam keadaan perawatan inap maupun pasien rawat jalan yang sekedar berobat di rumah sakit ${ }^{6,8}$.

Hasil penelitian ini menunjukkan bahwa sebanyak 53\% masyarakat lebih setuju bahwa sistem pelayanan kesehatan rumah sakit syariah di Yogyakarta sesuai dengan syariat islam. Hasil penelitian Sunawi di RSIS telah menerapkan nilai-nilai dan prinsip syariah dalam melakukan pelayanan medis dan keperawatan pada pasien, yaitu Rabbaniyah, Akhlaqiyah, Al Waqi'iyah dan Insaniya $^{5}$, sehingga dapat disimpulkan bahwa sistem pelayanan medis yang dibarengi dengan syariat-syariat islam akan membuat pasien menjadi nyaman dan merasa puas terhadap setia pelayanan medis yang diberikan dokter maupun perawat pada rumah sakit syariah. 
Sebagian besar masyarakat setuju bahwa Rumah Sakit syariah adalah RS yang menjalankan kegiatan usaha pelayanan kesehatan berdasarkan prinsip syariah. Rumah sakit syariah merupakan rumah sakit yang telah memiliki sertifikasi dari Dewan Syariah Nasional (DSN) yang di dalam nya terdapat dua standar penilaian penting dalam rumah sakit syariah, yaitu standar pengelolaan rumah sakit dan standar pelayanan pasien rumah sakit. Menurut MUKISI, rumah sakit syariah adalah rumah sakit yang aktivitasnya berdasarkan Maqashid al Syariah al Islamiyah. Hal ini sesuai dengan konsep maqashid syariah menurut Imam Syatibi yaitu memelihara agama (khifdz ad-diin), memelihara jiwa (khifdz an-nafs), memelihara keturunan (khifdz an-nasl), memelihara akal (khifdz al$a q l)$, dan memelihara harta $(k h i f d z \text { al-mal })^{9}$. Perdana, mengatakan bahwa implementasi yang semakin tinggi dari konsep pelayanan berbasis islami akan semakin meningkatkan kepuasan pasienterhadap pelayanan kesehatan tersebut ${ }^{10}$.

Rumah sakit dengan pelayanan berbasis syariah merupakan rumah sakit yang menjalankan seluruh aktifitas dengan berlandaskan maqashid al-syariah alislamiyah yang artinya menjaga agama, menjaga hidup, menjaga akal, menjaga keturunan dan menjaga harta. Maqasih syariah adalah jalur pedoman dari segala sesuatu yang tidak boleh bertolak belakang dengan prinsip-prinsip syariah ${ }^{6}$. Berdasarkan hasil penelitian, masyarakat sebagian besar setuju bahwa rumah sakit syariah juga memiliki prinsip sosial. Penelitian yang dilakukan Yusuf menunjukkan bahwa RS Islam Banjarmasin mengelola zakat, infaq dan shadaqah $\mathrm{RS}$ islam yang juga bekerja sama dengan lembaga lazismu ${ }^{8}$.

\section{Kesimpulan}

Berdasarkan uraian dari penelitian dan pembahasan maka diperoleh kesimpulan bahwa masyarakat setuju dan paham mengenai konsep rumah skait syariah yang diterapkan oleh rumah sakit yang ada di Yogyakarta, dan pelayanan kesehatan sesuai dengan syariah islam dibutuhkan oleh masyarakat untuk menjamin keamanan dan kenyamaan pasien saat berobat di rumah sakit syariah tersebut.

\section{Saran}

Saran yang bermanfaat bagi pihak-pihak yang bersangkutan adalah :

1. Kebutuhan layanan Rumah sakit syariah yang terus meningkat sehingga perlunya pengembangan rumah sakit-rumah sakit yang berbasis syariah

2. Peningkatan sarana dan prasarana lainnya terutama yang menunjang agar dapat terlaksana penyelenggaraan pelayanan rumah sakit yang menyeluruh sesuai syariat islam di rumah sakit 


\section{Daftar Pustaka}

1. MUI, DSN, MUKISI. 2017. Standar \& Instrumen Sertifikasi Rumah Sakit Syariah. Jakarta.

2. MUKISI. 2017. Pedoman Standar Pelayanan Minimal Rumah Sakit Syariah Dan Indikator Mutu Wajib Syariah. Jakarta.

3. Sari Dwp, Abdurrouf M, Rismawati R. 2018. Relationship Between ShariaBased Nursing Services And Patient Loyality At Islamic Hospital. Nurscope $J$ Penelit Dan Pemikir Ilm Keperawatan. 2018;4(7):109-17.

4. Pratiwi Hafid H. 2016. Pengaruh Pelayanan Dengan Prinsip-Prinsip Syariah Terhadap Kepuasan Pasien Pada Rs Ibnu Sina Makassar. RepositoryuinMakasar.

5. Sunawi. 2012. Konsep Pelayanan Kesehatan Islami Di Rumah Sakit (Tinjauan Aplikasi Di Rumah Sakit Islam Surakarta). Universitas Muhammadiyah Surakarta.

6. Helida N. 2018. Efektivitas Pelayanan Berbasis Syariah Terhadap Kepuasan Pelanggan Pada Sektor Layanan Publik (Studi Kasus: RSUD Dr. Zainoel Abidin Kota Banda Aceh). Universitas Islam Negeri Ar-Raniry Darussalam, Banda Aceh.

7. Abdurrouf M, Rosalia C. 2018. Pelayanan Syariah Dalam Bidang Keperawatan Dengan Tingkat Kepuasan Pasien Di Rumah Sakit. Unissula Nurs Conf Call Pap Natl Conf. 2018;1(1):24-31.

8. Yusuf M.2019. Penyelenggaran Rumah Sakit Berdasarkan Prinsip Syariah: Studi Pada Rumah Sakit Islam Banjarmasin. At-Taradhi J Stud Ekon. 2019;9(2):76.

9. MUKISI. 2018. Penggagas Rumah Sakit Bersistem Syariah. Jakarta.

10. Perdana N, Hermansyah, Darmawan E, 2017. Impementasi Pelayanan Kesehatan Berbasis Islami Terhadap Kepuasan Pasien Di RSUD Meuraxa. Jukema. 2017;3(1):190-7. 